\title{
Appendix Carcinoma by AJCC v7 Stage
}

National Cancer Institute

\section{Source}

National Cancer Institute. Appendix Carcinoma by A/CC v7 Stage. NCI Thesaurus. Code C133733.

A term that refers to the staging of appendiceal carcinoma according to the American Joint Committee on Cancer, 7th edition. Carcinoid tumors are staged separately. (from AJCC 7th Ed.) 